\title{
Regioselectivity of the interaction of temozolomide with borane and boron trifluoride
}

\section{Okuma Emile Kasende, Jules Tshishimbi Muya \& Steve Scheiner}

\section{Structural Chemistry}

Computational and Experimental Studies of Chemical and Biological Systems

ISSN 1040-0400

Struct Chem

DOI 10.1007/s11224-015-0640-6

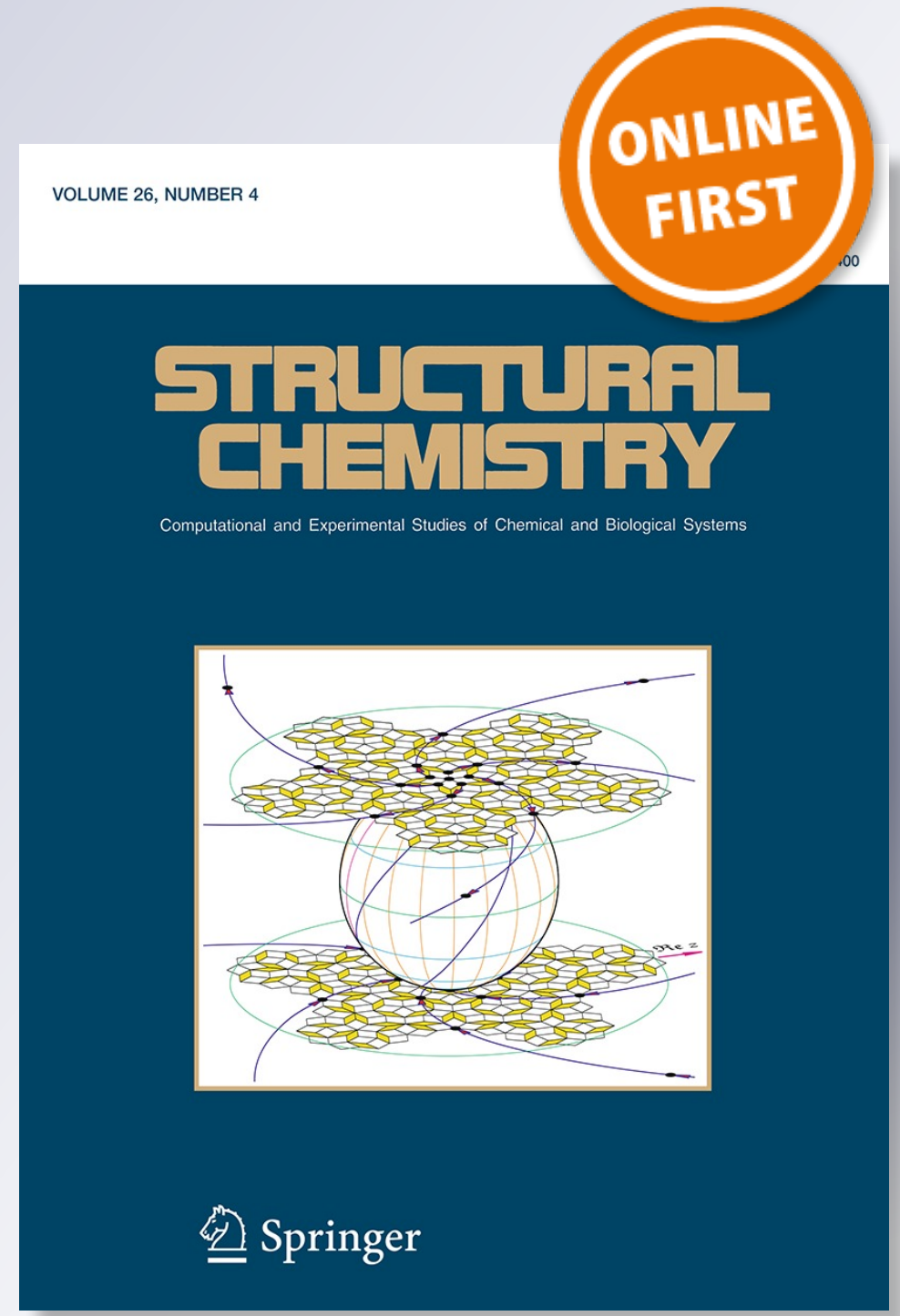

Springer 
Your article is protected by copyright and all rights are held exclusively by Springer Science +Business Media New York. This e-offprint is for personal use only and shall not be selfarchived in electronic repositories. If you wish to self-archive your article, please use the accepted manuscript version for posting on your own website. You may further deposit the accepted manuscript version in any repository, provided it is only made publicly available 12 months after official publication or later and provided acknowledgement is given to the original source of publication and a link is inserted to the published article on Springer's website. The link must be accompanied by the following text: "The final publication is available at link.springer.com". 


\title{
Regioselectivity of the interaction of temozolomide with borane and boron trifluoride
}

\author{
Okuma Emile Kasende $^{1} \cdot$ Jules Tshishimbi Muya $^{1} \cdot$ Steve Scheiner $^{2}$
}

Received: 7 July 2015/Accepted: 11 July 2015

(c) Springer Science+Business Media New York 2015

\begin{abstract}
MP2 and B3LYP calculations are used to predict the most favorable site of temozolomide toward $\mathrm{BH}_{3}$ and $\mathrm{BF}_{3}$ which are classical Lewis acids. Binding energies, charge transfers, and bond length perturbations of the temozolomide in various complexes indicate that the $\mathrm{N}_{12}$ atom is the preferred attack site for $\mathrm{BH}_{3}$, while $\mathrm{BF}_{3}$ prefers the $\mathrm{O}_{17}$ atom. The interactions are quite strong, as much as $100 \mathrm{~kJ} / \mathrm{mol}$ for $\mathrm{BH}_{3}$ and more than $60 \mathrm{~kJ} / \mathrm{mol}$ for $\mathrm{BF}_{3}$. The molecular electrostatic potential surrounding temozolomide is most negative around the $\mathrm{O}$ atoms, which is unable to explain the energetic order of binding of the Lewis acids.
\end{abstract}

Keywords MP2 - B3LYP · MEP · Noncovalent bond

\section{Introduction}

The temozolomide (TMZ) molecule (Fig. 1), characterized by a fused pair of heterocyclic rings containing a total of five $\mathrm{N}$ atoms, as well as a carbonyl and one amide group, continues to attract the attention of numerous research groups because of its applications in medicine such as cytotoxic pro-drug for the treatment of astrocytoma,

This paper is dedicated to Professor Magdolna Hargittai on the occasion of her 70th birthday.

Steve Scheiner

scheiner@cc.usu.edu; steve.scheiner@usu.edu

Okuma Emile Kasende

okuma.kasende@aggiemail.usu.edu

1 Faculty of Sciences, University of Kinshasa, B.P. 190, Kinshasa XI, Democratic Republic of the Congo

2 Department of Chemistry and Biochemistry, Utah State University, Logan, UT 84322-0300, USA aggressive brain tumor, glioblastoma multiform, and melanoma [1].

Laboratory studies and clinical trials have investigated whether the anticancer potency of TMZ might be augmented by combining it with other pharmacologic agents. Some clinical trials have indicated that the addition of chloroquine is suspected to be beneficial for the treatment of glioma patients [2,3]. Likewise, investigations on the effects of TMZ and quercetin on cell death in the human astrocytoma cell line MOGGCCM indicate that quercetin acts in concert with TMZ when used in combination rather than in separate pharmacological applications [4, 5]. Along the same line, in combination, TMZ and irinotecan induced complete responses in four neuroblastomas, two rhabdomyosarcomas, and the glioblastoma line [6]. The activity of the combination was significantly greater than the activity of either agent administered alone in four tumor lines [6]. Nevertheless, the mechanism of the TMZ action remains largely unknown [7].

There are two possible ways for TMZ to act in synergy with chloroquine or quercetin and irinotecan. In one mode, TMZ can act together with one of them simultaneously on different parts of DNA. Alternatively, TMZ can form complexes with the other agents, thus having cooperative effect on the DNA. In this last case, the interactions between TMZ and other pharmacologic agents forming supramolecular complexes are probably noncovalent, consistent with the ubiquitous role of noncovalent interactions in many biological processes [8-18]. The investigation and understanding of these noncovalent interactions has become one of the major goals of modern chemistry. Noncovalent interactions [12-14] form the basis of what is usually called "supramolecular interactions." However, quantitative elucidation of the thermodynamics solely by means of ab initio electronic structure theory remains an 


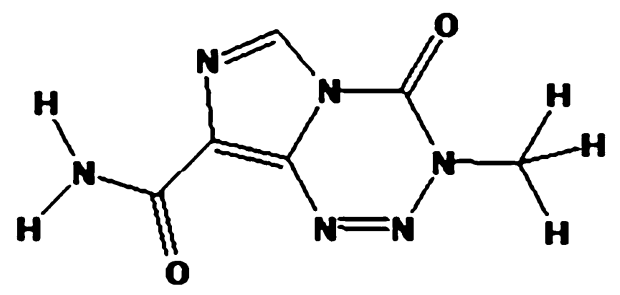

Fig. 1 Structure of temozolomide (TMZ)

elusive target, and a phenomenological view of the binding mechanism prevails $[15,16]$.

As TMZ is a polyfunctional heterocyclic base containing two carbonyl groups and six nitrogen atoms as possible electron donor sites, it would be useful to analyze its potential noncovalent interactions, e.g., hydrogen bond or electrophilic interactions, with other molecules. Our previous study applied computational methods to predict the most favorable site of TMZ toward attack by a water molecule [19]. The outcome of these investigations revealed the terminal amide group of the TMZ as the preferred attack site where water can act as simultaneous proton donor and acceptor (Fig. 2) [19].

However, H-bonds are not the only sorts of interactions in which TMZ can participate. Another important scenario involves more general electrophilic interactions with Lewis acids. As an example, our recent DFT study to determine the stability of the complexes formed between the $\mathrm{N}$ and $\mathrm{O}$ sites of 3-methyl-4-pyrimidone and 1-methyl-2-pyrimidone found their behavior toward Lewis acids especially intriguing [20]. That study pointed out a strong regioselectivity with borane and its derivatives preferring the nitrogen site in both pyrimidone isomers, while a preference for oxygen is observed for alkali acids in 3-methyl-4-pyrimidone. The complexation of 1-methyl-2-pyrimidone with these hard alkali acids did not show any discrimination between the two sites due to the presence of a continuous delocalized electron density region between the $\mathrm{N}$ and $\mathrm{O}$ atoms.

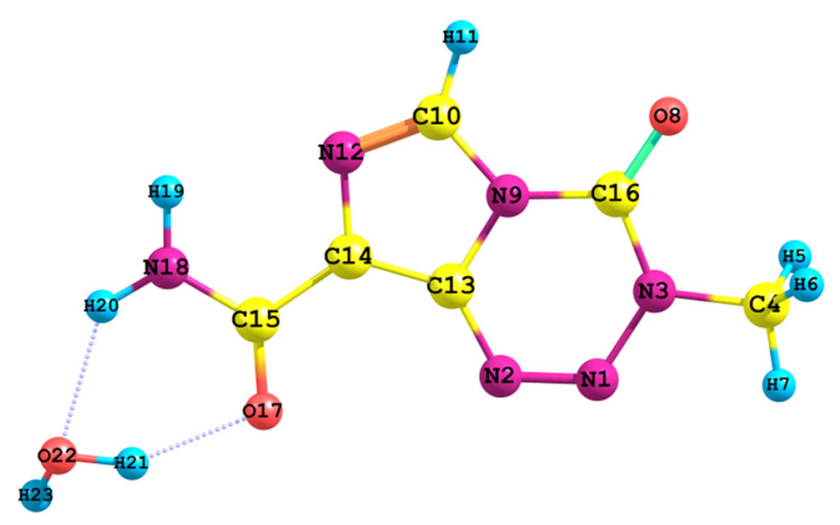

Fig. 2 Water-TMZ complex derived from [19]
However, to the best of our knowledge, and despite the biological importance of this molecule, no experimental or theoretical data concerning the regioselectivity of the TMZ molecule in the context of such electrophilic interactions have yet been reported. The interactions between TMZ and $\mathrm{BF}_{3}$ or $\mathrm{BH}_{3}$ partners are of the Lewis acid base type, and one is tempted to use Pearson's hard and soft acids/bases principle [21] as a starting point. However, this set of principles represents only a guide, and care should be exercised particularly if both the reactants are not of the hard type (hardhard interactions), and in intermediate nonmatching cases, predictions are more problematic.

This work considers $\mathrm{BH}_{3}$ and $\mathrm{BF}_{3}$ adducts which represent soft and hard Lewis acids, respectively, and thus cover a range. Each boron atom contains an empty $2 p$ orbital, perpendicular to the molecular plane. Thus, the main interaction between TMZ and a boron Lewis acid is the electron donation from the oxygen or nitrogen lone pair of the TMZ molecule into the empty orbital on the B atom of the Lewis acid. This work examines all of the potential adducts of TMZ with $\mathrm{BH}_{3}$ and $\mathrm{BF}_{3}$ and elucidates the preferred binding sites. As such, one can compare the interaction energies of different $\mathrm{N}$-bound and O-bound isomers, and derive the preferred binding sites, and the energetic advantage of each.

\section{Computational methods}

Geometry optimizations were performed using both MP2 and DFT with the hybrid B3LYP functional and a $6-31+G(d, p)$ set $[18,22]$. After consideration of various sites, six $\mathrm{BH}_{3}-\mathrm{TMZ}$ and $\mathrm{BF}_{3}-\mathrm{TMZ}$ conformers were obtained. Vibrational analysis showed each structure to be a true minimum.

The binding energy of each complex was computed as the difference between the energy of each complex and the relaxed structures of the monomers. These binding energies were corrected for the basis set superposition error (BSSE) [23, 24] by the Boys and Bernardi [25] counterpoise correction procedure.

The molecular electrostatic potential (MEP), the interaction of a unit positive charge at a given point $\vec{r}$ with reference to a molecular charge distribution, is evaluated by [26]:

$v(\mathbf{r})=\sum_{A} \frac{Z_{A}}{\left|\mathbf{R}_{\mathrm{A}}-\mathbf{r}\right|}-\int \frac{\rho(\mathbf{r})}{\left|\mathbf{r}^{\prime}-\mathbf{r}\right|} \mathrm{d} \mathbf{r}$

where $\rho(\mathbf{r})$ is the molecular electron density function; the summation over $A$ runs over all nuclei with charge $Z_{A}$ and distance $R_{A}$. All calculations were performed using the Gaussian 09 software package [27, 28]. Atomic charges 
and charge transfer energies were assessed by $\mathrm{NBO}$ as implemented in Gaussian 09. GaussView and Chemcraft [29] programs were used for visualization [27].

\section{Results}

Table 1 reports in the first column the MP2 relative energies of the various optimized dimers combining TMZ with $\mathrm{BF}_{3}$, with the N12 complex taken as reference point. (Structures are displayed in Fig. 3.) The O17 site is slightly more attractive than $\mathrm{N} 12$, but the other four complexes are much less tightly bound. This conclusion survives the addition of zero-point vibrational energies, as illustrated in the second column of Table 1. The binding energies of each complex are displayed in the succeeding columns of Table 1, both without and with ZPE included. $\mathrm{BF}_{3}$ is bound to $\mathrm{N} 12$ and $\mathrm{O} 17$ by $60 \mathrm{~kJ} / \mathrm{mol}$, diminishing to nearly $50 \mathrm{~kJ} / \mathrm{mol}$ upon ZPE correction. Binding energies to the other sites are much smaller in magnitude, $<13 \mathrm{~kJ} / \mathrm{mol}$, and even positive in one instance. The optimized B $\cdots \mathrm{N} / \mathrm{O}$ distances in the next column of Table 1 are largely reflective of the energetics. The strongly bound complexes at N12 and $\mathrm{O} 17$ are shorter than $1.7 \AA$, while the others are as long as $2.6 \AA$.

For purposes of comparison, the same data are reported in Table 2 for DFT calculations using the B3LYP functional, with the same basis set. The main trends are repeated here: $\mathrm{O} 17$ provides the strongest binding site, followed by N12, with the others much less potent. However, there are several quantitative differences. In the first place, the difference between $\mathrm{O} 17$ and $\mathrm{N} 12$ is exaggerated by B3LYP, from $<1$ to $12 \mathrm{~kJ} / \mathrm{mol}$. Another difference is that $\mathrm{N} 2$ does not offer a stable binding site; a $\mathrm{BF}_{3}$ molecule placed here shifts over to the much more stable O17. The very long $\mathrm{B} \cdots \mathrm{O} / \mathrm{N}$ distances predicted by MP2 for $\mathrm{N} 1$ and O8 sites are much shorter for B3LYP, well $<2 \AA$.

The corresponding parameters for the binding of $\mathrm{BH}_{3}$ to TMZ are displayed in Tables 3 and 4, along with Fig. 4. Focusing first on the MP2 data, N12 serves as the preferred site of binding, as opposed to $\mathrm{O} 17$ as was the

Table 1 Energetics $(\mathrm{kJ} / \mathrm{mol})$ of interaction of $\mathrm{BF}_{3}$ at various sites of the TMZ molecule at MP2/6-31+G(d,p) level

\begin{tabular}{lrrrrrl}
\hline & \multicolumn{1}{c}{$E_{\text {rel }}$} & \multicolumn{1}{c}{$E_{\text {rel }}+$ ZPE } & \multicolumn{1}{l}{$E_{\mathrm{b}}$} & $E_{\mathrm{b}}+\mathrm{ZPE}$ & $R, \AA$ & $\Delta Q, \mathrm{e}$ \\
\hline $\mathrm{O}_{17}$ & -0.79 & -1.92 & -60.82 & -49.94 & 1.64 & 0.238 \\
$\mathrm{~N}_{12}$ & 0.00 & 0.00 & -60.04 & -48.02 & 1.69 & 0.249 \\
$\mathrm{~N}_{18}$ & 36.18 & 35.62 & -23.86 & -12.39 & 1.79 & 0.225 \\
$\mathrm{~N}_{1}$ & 41.93 & 37.32 & -18.11 & -10.69 & 2.60 & 0.019 \\
$\mathrm{O}_{8}$ & 40.12 & 41.95 & -19.92 & -6.06 & 2.54 & 0.171 \\
$\mathrm{~N}_{2}$ & 53.11 & 51.74 & -6.92 & 3.72 & 1.82 & 0.190 \\
\hline
\end{tabular}

case for $\mathrm{BF}_{3}$. Indeed, there is a wide margin of preference for N12, nearly $20 \mathrm{~kJ} / \mathrm{mol}$. Secondly, the binding is considerably stronger for $\mathrm{BH}_{3}$, as much as $101 \mathrm{~kJ} / \mathrm{mol}$ at the N12 site. Indeed, it is not only N12, but all sites bind much more strongly to $\mathrm{BH}_{3}$ than to $\mathrm{BF}_{3}$. The weakest interaction occurs at $\mathrm{O} 8$, but even here $\mathrm{BH}_{3}$ is bound by more than $30 \mathrm{~kJ} / \mathrm{mol}$. Consonant with the stronger binding, the intermolecular $\mathrm{B} \cdots \mathrm{N} / \mathrm{O}$ distances are also shorter for $\mathrm{BH}_{3}$. B3LYP again reproduces the qualitative trends of MP2 and is even fairly good in a quantitative sense.

As might be expected, there is a good deal of charge that is transferred from TMZ to the Lewis acid. This quantity $\Delta Q$ was evaluated as the sum of atomic NBO charges on the Lewis acid and is displayed as the last column of Tables 1, 2, 3 and 4. At the MP2 level, the charge transfer reaches as high as $0.32 \mathrm{e}$ in the complex where $\mathrm{BH}_{3}$ attacks the $\mathrm{N} 12$ atom of TMZ. There is a fair, but by no means precise, correlation between $\Delta Q$ and the energetic strength of the binding. For example, the aforementioned $\mathrm{BH}_{3}$ complex with $\mathrm{N} 12$ is the strongest one observed with a binding energy of $101 \mathrm{~kJ} / \mathrm{mol}$. The two strongest complexes of $\mathrm{BF}_{3}$ with $\mathrm{TMZ}$ are associated with $\mathrm{O} 17$ and N12, which have the largest $\Delta Q$ in Table 1 . On the other hand, the complex with N18 is very much weaker, yet still has a value of $\Delta Q$ very close to those for $\mathrm{O} 17$ and N12. In fact, even the weakest complex of $\mathrm{BF}_{3}$ with $\mathrm{N} 2$, barely bound at all, shows a large charge transfer of 0.19 e. On a similar note, the charge transfers for $\mathrm{BH}_{3}$ in Table 3 are similar to the values for $\mathrm{BF}_{3}$, even though the binding energies of the former are generally quite a bit larger. It is finally noted that the B3LYP charge transfers in Tables 2 and 4 are generally quite similar to the corresponding MP2 values.

Despite these very substantial binding energies, there are relatively minor perturbations of the internal geometry of TMZ. Changes in the bond lengths within TMZ caused by each site of complexation are indicated in Figs. 3 and 4, in $\mathrm{m} \AA$. For example, the most strongly bound complex of $\mathrm{BF}_{3}$ occurs at $\mathrm{N} 12$ and $\mathrm{O} 17$. This association elongates the two $\mathrm{N}_{12}-\mathrm{C}$ bonds by 4 and $9 \mathrm{~m} \AA$. Association with $\mathrm{O} 17$, also a strongly bound complex, causes the $\mathrm{C}=\mathrm{O} 17$ bond to stretch by $24 \mathrm{~mA}$, and the two neighboring $\mathrm{CN}$ bonds to contract by some $20 \mathrm{~m} \AA$. It is worth noting the absence of a clear correspondence between the strength of the interaction and the perturbation of the neighboring bond lengths. For example, although the complex with N18 is only moderate in strength, it nonetheless results in the largest bond length perturbation wherein the neighboring NC bond elongates by $89 \mathrm{~m} \AA$. The corresponding bond length changes induced by complexation with $\mathrm{BH}_{3}$ are displayed in Fig. 4. Again, there is little relation between strength of interaction and internal bond perturbation. 
Fig. 3 MP2 equilibrium geometries of complexes of $\mathrm{TMZ}$ with $\mathrm{BF}_{3}$. Intermolecular distances are in $\AA$. Perturbations of neighboring bond lengths within $\mathrm{TMZ}$ are shown in $\mathrm{m} \AA$

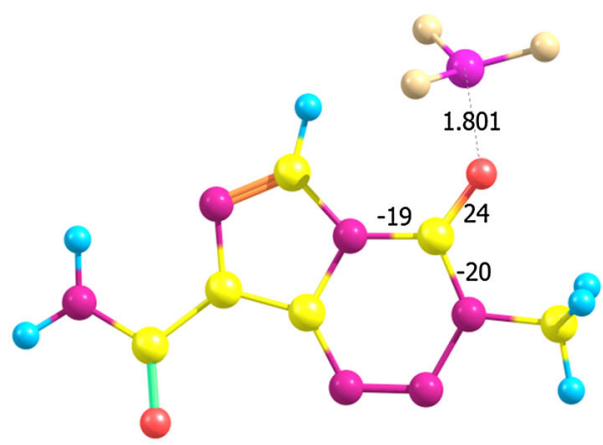

(a) 017

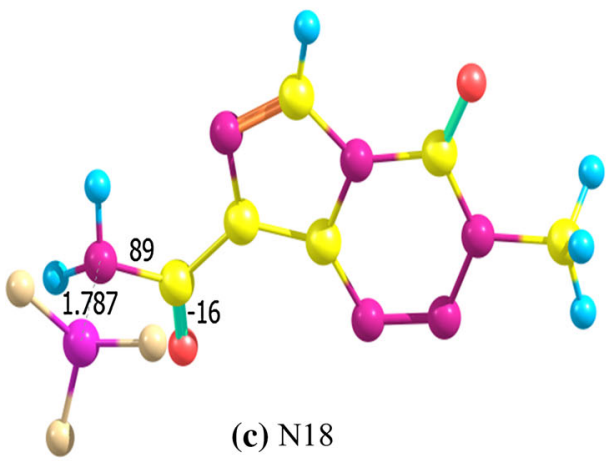

(c) $\mathrm{N} 18$

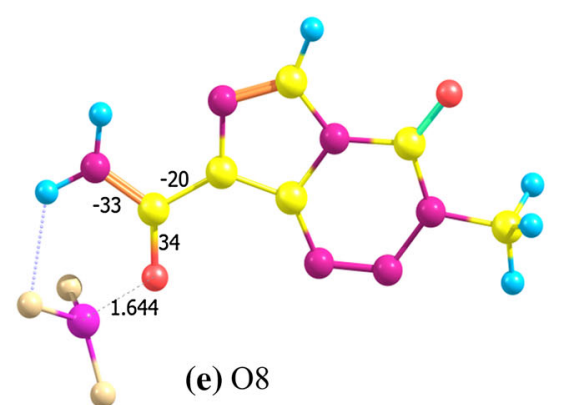

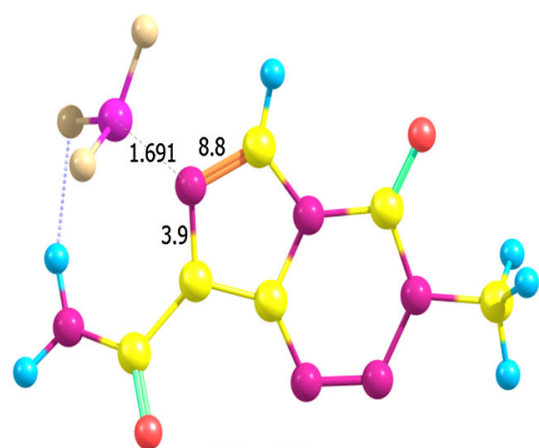

(b) $\mathrm{N} 12$
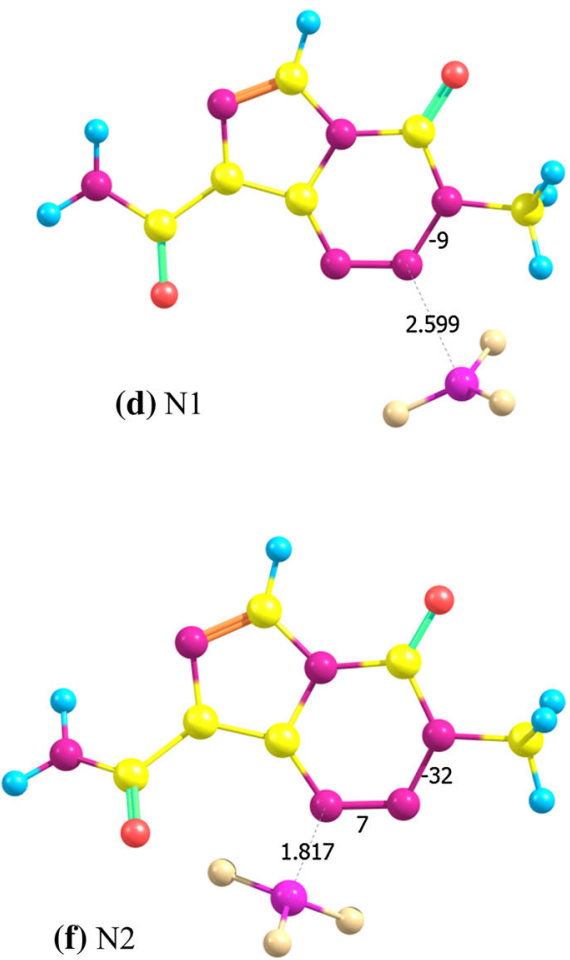

Table 2 Energetics $(\mathrm{kJ} / \mathrm{mol})$ of interaction of $\mathrm{BF}_{3}$ at various sites of the TMZ molecule at B3LYP/6-31+G(d,p) level

\begin{tabular}{lrlcccc}
\hline & $E_{\text {rel }}$ & $E_{\text {rel }}+$ ZPE & \multicolumn{1}{l}{$E_{\mathrm{b}}$} & $E_{\mathrm{b}}+\mathrm{ZPE}$ & $R, \AA$ & $\Delta Q, \mathrm{e}$ \\
\hline $\mathrm{O}_{17}$ & -12.08 & -11.20 & -65.03 & -57.40 & 1.61 & 0.266 \\
$\mathrm{~N}_{12}$ & 0.00 & 0 & -52.95 & -46.21 & 1.67 & 0.267 \\
$\mathrm{~N}_{18}$ & 41.03 & 41.56 & -11.93 & -4.65 & 1.79 & 0.059 \\
$\mathrm{~N}_{1}$ & 45.01 & 42.87 & -7.95 & -3.34 & 1.90 & 0.012 \\
$\mathrm{O}_{8}$ & 40.51 & 36.65 & -12.44 & -9.56 & 1.74 & 0.213 \\
$\mathrm{~N}_{2}$ & - & - & - & - & - & - \\
\hline
\end{tabular}

$\mathrm{BF}_{3}$ shifts to $\mathrm{O}_{17}$ when placed on $\mathrm{N}_{2}$

Although the complex with N12 is the strongest, the bond length changes are $<10 \mathrm{m \AA}$, some of the smallest perturbations of all.
Table 3 Energetics $(\mathrm{kJ} / \mathrm{mol})$ of interaction of $\mathrm{BH}_{3}$ at various sites of the TMZ molecule at MP2/6-31+G(d,p) level

\begin{tabular}{lrlrlll}
\hline & $E_{\text {rel }}$ & $E_{\text {rel }}+$ ZPE & \multicolumn{1}{l}{$E_{\mathrm{b}}$} & $E_{\mathrm{b}}+\mathrm{ZPE}$ & $R, \AA$ & $\Delta Q, \mathrm{e}$ \\
\hline $\mathrm{N}_{12}$ & 0.00 & 0 & -101.05 & -78.59 & 1.62 & 0.320 \\
$\mathrm{O}_{17}$ & 22.36 & 19.72 & -78.69 & -58.67 & 1.61 & 0.265 \\
$\mathrm{~N}_{1}$ & 30.90 & 30.71 & -70.15 & -47.68 & 1.61 & 0.180 \\
$\mathrm{~N}_{18}$ & 39.17 & 39.10 & -61.88 & -39.29 & 1.73 & 0.275 \\
$\mathrm{~N}_{2}$ & 43.52 & 42.48 & -57.53 & -35.41 & 1.63 & 0.255 \\
$\mathrm{O}_{8}$ & 69.91 & 65.04 & -31.14 & -13.35 & 1.68 & 0.199 \\
\hline
\end{tabular}

In a number of cases in the literature, the strength of the interaction has been directly related to the MEP of the molecules of interest. Figure 5 illustrates the MEP 
Table 4 Energetics $(\mathrm{kJ} / \mathrm{mol})$ of interaction of $\mathrm{BH}_{3}$ at various sites of the TMZ molecule at B3LYP/6-31+G(d,p) level

\begin{tabular}{lrlllll}
\hline & $E_{\text {rel }}$ & $E_{\text {rel }}+$ ZPE & $E_{\mathrm{b}}$ & $E_{\mathrm{b}}+\mathrm{ZPE}$ & $R, \AA$ & $\Delta Q, \mathrm{e}$ \\
\hline $\mathrm{N}_{12}$ & 0.00 & 0 & -95.68 & -79.06 & 1.65 & 0.315 \\
$\mathrm{O}_{17}$ & 7.69 & 7.22 & -87.99 & -71.84 & 1.65 & 0.261 \\
$\mathrm{~N}_{1}$ & 22.35 & 22.43 & -73.33 & -56.62 & 1.66 & 0.250 \\
$\mathrm{~N}_{18}$ & 42.58 & 44.42 & -53.09 & -34.63 & 1.74 & 0.303 \\
$\mathrm{~N}_{2}$ & 43.98 & 43.07 & -51.69 & -35.98 & 1.67 & 0.247 \\
$\mathrm{O}_{8}$ & 57.62 & 55.06 & -38.05 & -23.99 & 1.76 & 0.250 \\
\hline
\end{tabular}

surrounding the TMZ molecule; the MEPs of $\mathrm{BF}_{3}$ and $\mathrm{BH}_{3}$ are displayed in Fig. 6. The negative regions are red, and the positive areas are blue. The most negative region surrounds O17, followed by O8, and then N2 and N1 and N12. Purely electrostatic attraction to the positive potential above the $\mathrm{B}$ atom of $\mathrm{BF}_{3}$ would thus follow this same order. However, even though the negative region around N12 is rather weak, this atom still serves as one of the two strongest binding sites for $\mathrm{BF}_{3}$. And even though there is no negative potential in the vicinity of $\mathrm{N} 18$, this atom nevertheless serves as a reasonably strong binding site, surpassed only by $\mathrm{O} 17$ and N12. Another example arises with $\mathrm{O} 8$; despite a very negative potential surrounding it, $\mathrm{O} 8$ offers only weak binding to $\mathrm{BF}_{3}$. The situation with $\mathrm{BH}_{3}$ is similarly poorly correlated. N12 is the strongest binding site, but has only a weak negative region around it. And again, despite the absence of a negative potential, N18 represents a strong binding site. It is thus clear that the binding forces are not controlled by electrostatics.

One can thus attempt to rationalize the energetic ordering as a composite of electrostatic attraction and charge transfer effects. This importance of the latter is perhaps best illustrated by comparison of $\mathrm{O} 17$ and $\mathrm{N} 12$ as binding sites. O17 represents the area with the most
Fig. 4 MP2 equilibrium geometries of complexes of $\mathrm{TMZ}$ with $\mathrm{BH}_{3}$. Intermolecular distances are in $\AA$. Perturbations of neighboring bond lengths within $\mathrm{TMZ}$ are shown in $\mathrm{mA}$

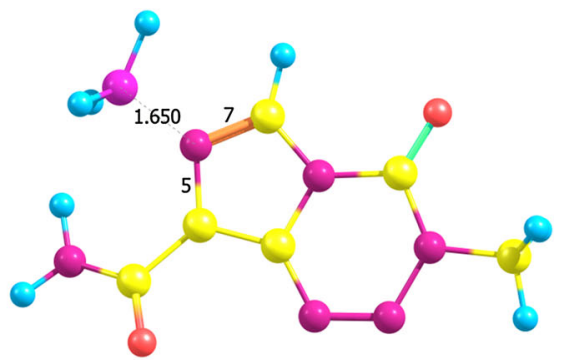

(a) $\mathrm{N} 12$

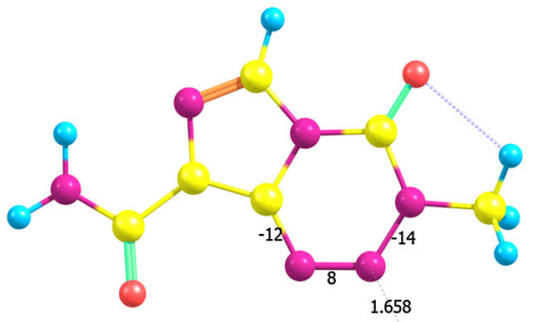

(c) $\mathrm{N} 1$
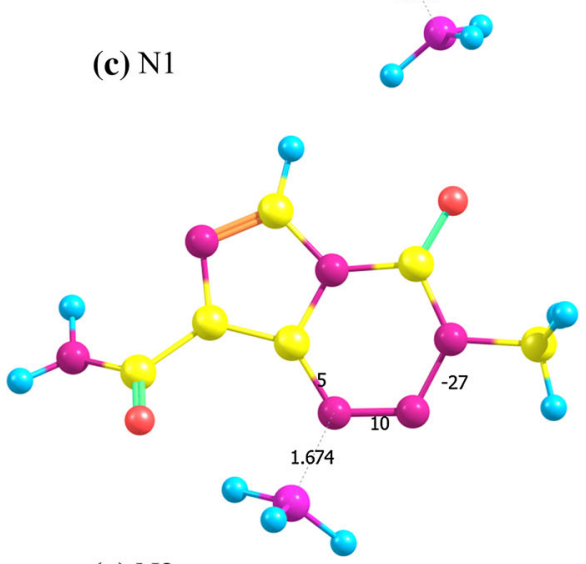

(e) $\mathrm{N} 2$

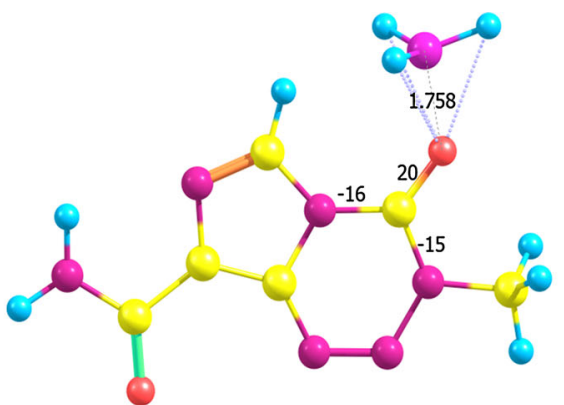

(b) $\mathrm{O} 17$
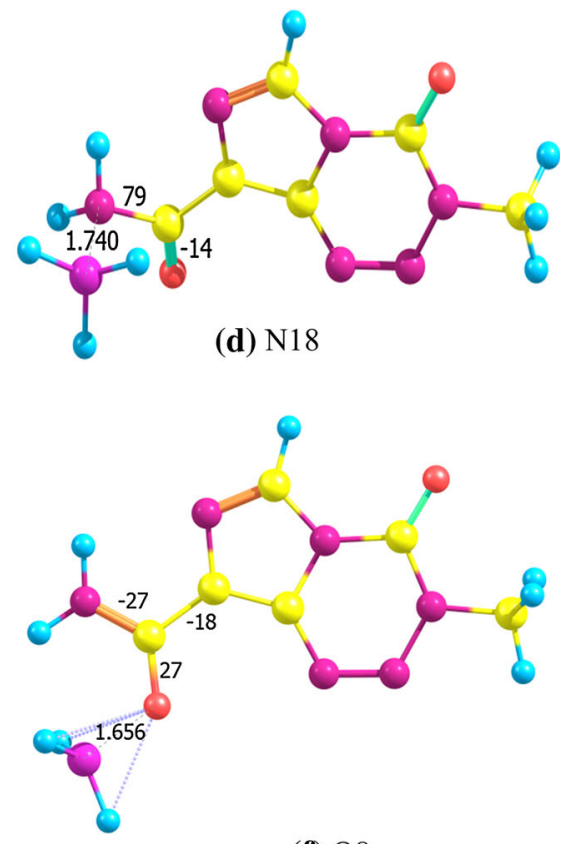

(f) $\mathrm{O} 8$ 


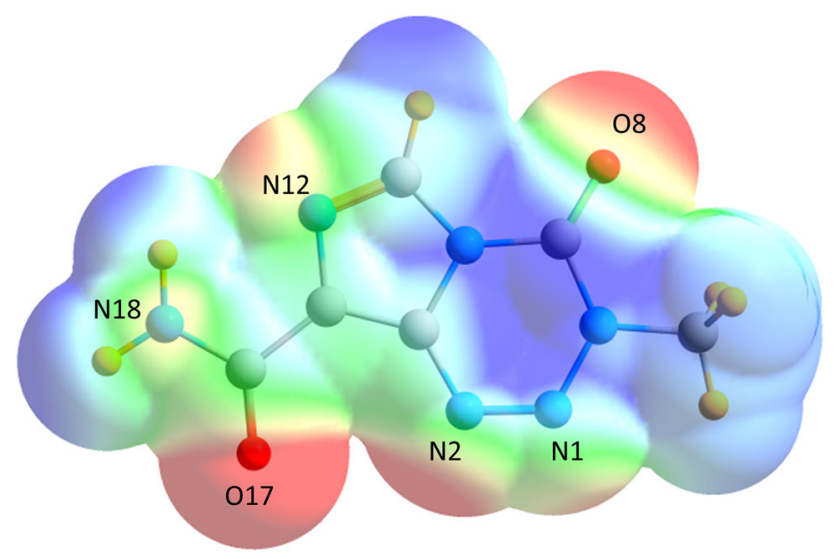

Fig. 5 Molecular electrostatic potential surrounding TMZ on surface representing 1.5 times the van der Waals radius of each atom. Blue color indicates a potential of $+0.05 \mathrm{au}$, and red corresponds to -0.05 (Color figure online)

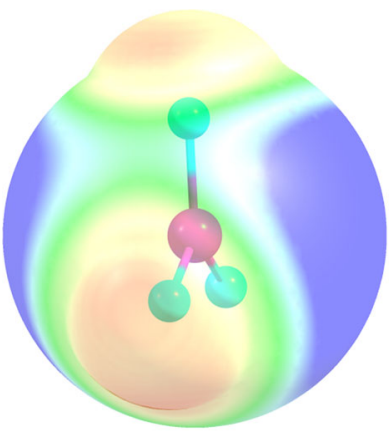

(a) $\mathrm{BF}_{3}$

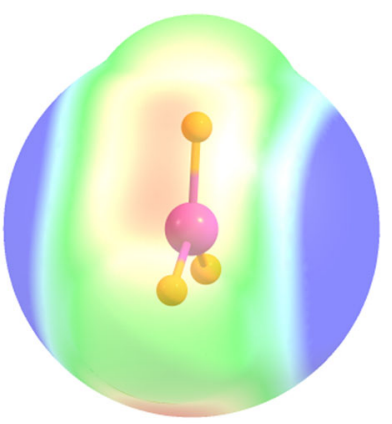

(b) $\mathrm{BH}_{3}$

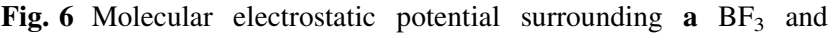
b $\mathrm{BH}_{3}$ on surface representing 1.5 times the van der Waals radius of each atom. Blue and red colors represent \pm 0.02 au, respectively, for $\mathrm{BF}_{3}$ and \pm 0.01 au for $\mathrm{BH}_{3}$ (Color figure online)

negative potential surrounding TMZ, whereas N12 lies in a much less negative area. Nonetheless, the similar charge transfer to these two sites of TMZ from $\mathrm{BF}_{3}$ overrides the MEP effect, and this Lewis acid binds to the two sites with roughly equal binding energy. In the case of $\mathrm{BH}_{3}$, the charge transfer from the N12 site is larger than that for O17, and the binding energy is similarly greater as well. On the other hand, electrostatics dominate other pairs of binding sites. The more negative MEP around $\mathrm{O} 17$ versus O8, N2, N1, or N18 cannot be surpassed by charge transfer considerations. For example, $\mathrm{O} 17$ is preferred by $\mathrm{BH}_{3}$ to N18, even though the charge transfer in the latter case surpasses that of the former.

These results can be placed in the context of similar interactions studied earlier. The stronger $\mathrm{BH}_{3}$ complexes compared to $\mathrm{BF}_{3}$ mirrors previous studies [20] on the interaction of these same molecules with pyrimidones. One can also compare the interactions [19] of TMZ with water. At the same MP2/6-31+G* level, the relevant binding energies span a range from 11 to $40 \mathrm{~kJ} / \mathrm{mol}$, weaker than those of the two Lewis acids. Water prefers association with $\mathrm{O} 17$, but the $\mathrm{OH} \bullet \bullet \mathrm{O} 17 \mathrm{H}$-bond is supplemented by a $\mathrm{N}_{18} \mathrm{H} \cdots \mathrm{O}_{\mathrm{w}} \mathrm{HB}$, so the $40 \mathrm{~kJ} / \mathrm{mol}$ can be considered a composite of both HBs. Even so, the total binding energy of $40 \mathrm{~kJ} / \mathrm{mol}$ is smaller than the maximum value for either $\mathrm{BH}_{3}$ or even $\mathrm{BF}_{3}$. Indeed, most of the complexes of water with TMZ involve a pair of HBs, which underscores the weakness of each individual $\mathrm{HB}$ when compared to $\mathrm{BH}_{3}$ or $\mathrm{BF}_{3}$, each of which has only a single $\mathrm{N} / \mathrm{O} \cdots \mathrm{B}$ interaction. The exceptions to this rule concern the interactions of $\mathrm{BF}_{3}$ at the $\mathrm{O} 17$ site where there is a possible auxiliary $\mathrm{NH} \cdots \mathrm{F}$ HB. Although the $R(\mathrm{H} \cdots \bullet \mathrm{F})$ distance is only $1.96 \AA$, the bond is highly bent, with $\theta(\mathrm{NH} \cdots \mathrm{F})=127^{\circ}$.

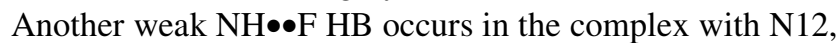
with $R(\mathrm{H} \cdots \mathrm{F})=1.90 \AA$ and $\theta(\mathrm{NH} \cdots \mathrm{F})=154^{\circ}$. Water's first choice of $\mathrm{O} 17$ as a binding site does mirror the two Lewis acids where this site is clearly one of the preferred locations. Lastly, very recent work [30] confirms the considerably stronger interactions of $\mathrm{BH}_{3}$ as compared to $\mathrm{BF}_{3}$ when interacting with a Lewis base.

Acknowledgments The authors thank Mireille Bilonda Kabuyi of the University of Venda, Republic of South Africa, for fruitful collaboration.

\section{References}

1. Hvizdos KM, Goa KL (1999) Temozolomide. CNS Drugs 12:237-243

2. Jacinto FV, Esteller M (2007) MGMT hypermethylation: a prognostic foe, a predictive friend. DNA Repair 6:1155-1160

3. Gilbert MR (2006) New treatments for malignant gliomas: careful evaluation and cautious optimism required. Ann Intern Med 144:371-373

4. Jakubowicz-Gil J, Langner E, Badwiul D, Wertel I (2013) Silencing of Hsp27 and Hsp72 in glioma cells as a tool for programmed cell death induction upon temozolomide and quercetin treatment. Toxicol Appl Pharm 273(3):580-589

5. Jakubowicz-Gil J, Langner E, Wertel I, Piersiak T, Rzeski W (2010) Temozolomide, quercetin and cell death in the MOGGCCM astrocytoma cell line. Chem Biol Interact 188:190-203

6. Houghton PJ, Stewart CF, Cheshire PJ, Richmond LB, Kirstein MN, Poquette CA, Tan M, Friedman HS, Brent TP (2000) Antitumor activity of temozolomide combined with irinotecan is partly independent of $O^{6}$-methylguanine-DNA methyltransferase and mismatch repair phenotypes in xenograft models. Clin Cancer Res 6:4110-4118

7. Denny BJ, Wheelhouse RT, Stevens MF et al (1994) NMR and molecular modeling investigation of the mechanism of activation of the antitumor drug temozolomide and its interaction with DNA. Biochemistry 33:9045-9051

8. Schuster P, Zundel G, Sandorfy C (eds) (1976) The hydrogen bond. recent developments in theory and experiments. NorthHolland Publishing Co, Amsterdam

9. Schuster P (1984) Hydrogen bonds. Springer, Berlin 
10. Jeffrey GA, Saenger W (1991) Hydrogen bonding in biological structures. Springer, Berlin

11. Scheiner S (1997) Hydrogen bonding. a theoretical perspective. Oxford University Press, New York

12. Gilli G, Gilli P (2009) The nature of the hydrogen bond. Oxford University Press, Oxford

13. Wieczorek R, Dannenberg JJ (2003) H-bonding cooperativity and energetics of $\alpha$-helix formation of five 17-amino acid peptides. J Am Chem Soc 125:8124-8129

14. Alabugin IV, Manoharan M, Peabody S, Weinhold F (2003) The electronic basis of improper hydrogen bonding: a subtle balance of hyperconjugation and rehybridization. J Am Chem Soc 125:5973-5987

15. Hernández-Soto H, Weinhold F, Francisco JS (2007) Radical hydrogen bonding: origin of stability of radical-molecule complexes. J Chem Phys 127:164102-164110

16. DelBene JE, Alkorta I, Elguero J (2011) An ab initio study of cooperative effects in ternary complexes $\mathrm{X}: \mathrm{CNH}: \mathrm{Z}$ with $\mathrm{X}$, $\mathrm{Z}=\mathrm{CNH}, \mathrm{FH}, \mathrm{ClH}, \mathrm{FCl}$, and $\mathrm{HLi}$ : structures, binding energies, and spin-spin coupling constants across intermolecular bonds. J Phys Chem Chem Phys 13:13951-13961

17. Thakur TS, Kirchner MT, Bläser D, Boese R, Desiraju GR (2011) Nature and strength of $\mathrm{C}-\mathrm{H} \cdots \mathrm{O}$ interactions involving formyl hydrogen atoms: computational and experimental studies of small aldehydes. Phys Chem Chem Phys 13:14076-14091

18. Lee CT, Yang W, Parr RG (1988) Development of the ColleSalvetti correlation-energy formula into a functional of the electron density. Phys Rev B 37:785-789

19. Kasende OE, Matondo A, Muzomwe M, Muya JT, Scheiner S (2014) Interaction between temozolomide and water: preferred binding sites. Comput Theor Chem 1034:26-29

20. Kasende OE, Muya JT, Broeckaert L, Maes G, Geerlings P (2012) Theoretical study of the regioselectivity of the interaction of 3-methyl-4-pyrimidone and 1-methyl-2-pyrimidone with Lewis Acids. J Phys Chem A 116:8008-8014

21. Pearson RG (1968) Hard and soft acids and bases. Part 1 fundamental principles. J Chem Educ 45:581-587

22. Becke AD (1993) Density-functional thermochemistry. III. The role of exact exchange. J Chem Phys 98:5648-5662

23. Gutowski M, van Duijneveldt van de Rijdt JGCM, van Lenthe JH, van Duijneveldt FB (1993) Accuracy of the Boys and Bernardi function counterpoise method. J Chem Phys 98:4728-4738

24. Latajka Z, Scheiner S (1987) Primary and secondary basis set superposition error at the SCF and MP2 levels: $\mathrm{H}_{3} \mathrm{~N}-\mathrm{Li}^{+}$and $\mathrm{H}_{2} \mathrm{O}-\mathrm{Li}^{+}$. J Chem Phys 87:1194-1204

25. Boys SF, Bernardi F (1970) The calculation of small molecular interactions by the difference of separate total energies. Some procedures with reduced errors. Mol Phys 19:553-566

26. Bonaccorsi R, Scrocco E, Tomasi J (1970) Molecular SCF calculations for the ground state of some three-membered ring molecules: $\left(\mathrm{CH}_{2}\right)_{3},\left(\mathrm{CH}_{2}\right)_{2} \mathrm{NH},\left(\mathrm{CH}_{2}\right)_{2} \mathrm{NH}_{2}{ }^{+},\left(\mathrm{CH}_{2}\right)_{2} \mathrm{O},\left(\mathrm{CH}_{2}\right)_{2} \mathrm{~S}$, $(\mathrm{CH})_{2} \mathrm{CH}_{2}$, and $\mathrm{N}_{2} \mathrm{CH}_{2}$. J Chem Phys 52:5270-5284

27. Dennington R, Keith T, Millan J (2009) GaussView, version 5. Semichem. Inc., Shawnee Mission

28. Frisch MJ, Trucks GW, Schlegel HB, Scuseria GE, Robb MA, Cheeseman JR, Scalmani G, Barone V, Mennucci B, Petersson GA et al (2009) Gaussian 09, revision A.02. Gaussian, Inc, Wallingford

29. Chemcraft, Grigoriy A. Andrienko. http://www.chemcraftprog. com

30. Grabowski SJ (2015) $\pi$-hole bonds: boron and aluminum Lewis Acid centers. ChemPhysChem 19:1470-1479 